\title{
Population-based impact on overall survival after the introduction of docetaxel as standard therapy for metastatic castration resistant prostate cancer
}

\author{
Robert R. Zielinski, MBBS, ${ }^{*}$ Arun A. Azad, PhD; ${ }^{*}$ Kim N. Chi, MD, FRCSC; ${ }^{*+}$ Scott Tyldesely, MD, FRCSC ${ }^{*+}$ \\ *BC Cancer Agency, Vancouver Centre, Department of Medical Oncology, British Columbia Cancer Agency, Vancouver BC; 'BC Cancer Agency, Vancouver Centre, Department of Radiation Oncology, University \\ of British Columbia, Vancouver, BC
}

Cite as: Can Urol Assoc J 2014;8(7-8):e520-3. http://dx.doi.org/10.5489/cuaj.2076 Published online August 11, 2014.

\section{Abstract}

Introduction: Utilization of docetaxel in patients with metastatic castration resistant prostate cancer (mCRPC) remains low despite its demonstrated survival benefit. In a population-based cohort, we sought to determine whether the introduction of docetaxel has improved overall survival (OS).

Methods: A retrospective review was conducted of mCRPC patients treated with palliative radiotherapy to bone in British Columbia, Canada. Patients in the pre-docetaxel era (pre-DOC, prior to general availability of docetaxel for $\mathrm{CRPC}$ ) received radiotherapy to bone (RT-B) from 1998 to 2001 and those in the docetaxel era (DOC) received radiotherapy from 2006 to 2009. Time of first radiotherapy to bone was used to select patients at a similar point in their disease state (i.e., onset of bone pain). The primary objective was to determine median OS in the two eras.

Results: Of the 919 patients in the pre-DOC era and the 957 in the DOC era, $7 \%$ and $37 \%$ received docetaxel, respectively. The median OS from time of first palliative RT was 7.5 months versus 10.3 months (hazard ratio [HR]: 0.79, 95\% confidence interval [CI] 0.72-0.87; $p<0.0001)$ in the pre-DOC and DOC cohorts, respectively. On multivariable analyses, both eras treated (HR 0.84; $p=0.001)$ and the receipt of docetaxel (HR 0.78; $p<0.001)$ were significantly associated with OS.

Conclusion: Although docetaxel penetrance was $<50 \%$, median OS was significantly improved in the DOC era compared to the pre-DOC era. This is the first study to demonstrate that docetaxel improves OS in mCRPC patients at a population level.

\section{Introduction}

Chemotherapeutic nihilism in the treatment of metastatic castration-resistant prostate cancer (mCRPC) was the norm until 2004, after which chemotherapy was increasingly used after 2 randomized phase III trials demonstrated an overall survival (OS) benefit with docetaxel. ${ }^{1,2}$ In recent years, the therapeutic landscape for mCRPC has rapidly evolved and there are now numerous systemic agents, including enzalutamide, ${ }^{3}$ abiraterone acetate, ${ }^{4}$ cabazitaxel, ${ }^{5}$ radium $-223^{6}$ and sipeleucel-T, ${ }^{7}$ demonstrated to extend OS in randomized phase III trials.

Despite the OS benefit seen with docetaxel in phase III trials, existing data from population-based studies indicate that less than one-third of mCRPC patients are treated with docetaxel. ${ }^{8,9}$ Several factors are likely to account for this relative under-utilization of docetaxel, including advanced age, poor performance status, absence of symptoms, patient unwillingness to accept chemotherapy, referral patterns to medical oncology and the increasing availability of other systemic agents. In light of the apparently low rates of docetaxel use in patients with $\mathrm{MCRPC}$, we sought to evaluate the utilization and impact, if any, on survival that docetaxel has had since its introduction as a standard treatment into a general population.

\section{Methods}

In British Columbia (BC), there is a single, centralized BC Cancer Agency (BCCA) providing all radiotherapy services in the province; all systemic therapies are either dispensed or reimbursed by the BCCA pharmacy. The population-based BCCA database was queried to identify all patients with adenocarcinoma of the prostate who received palliative radiotherapy to bone and these patients were subsequently linked to the provincial pharmacy database. Specific inclusion criteria for this study were a diagnosis of prostate cancer after 1983, being a resident of British Columbia and receiving a first course of palliative radiotherapy to bone at any point from 1998 to 2009. Approval was obtained from the University of British Columbia Research Ethics Board prior to commencing the study. 
Pre-DOC (pre-docetaxel) cohort patients received their first course of palliative radiotherapy to bone between 1998 and 2001 and the DOC (docetaxel) cohort patients received their first course of palliative radiotherapy to bone from 2006 to 2009. To minimize the risk of bias related to the time frame from diagnosis to first radiotherapy in the two eras, cases were only included if they had been diagnosed within 15 years of each era (i.e., cases diagnosis from 1983 to 2001 for the pre-DOC and 1991 to 2009 for the DOC era). Due to the delay in universal clinical adoption of docetaxel for $\mathrm{mCRPC}$ and the fact that BC was involved in enrolling men with $\mathrm{mCRPC}$ into docetaxel trials, a washout period from 2001 to 2006 was incorporated. The pre-DOC era started in 1998, the year when provincial wide pharmacy data and health records were computerized. The year 2009 was selected as the upper limit for diagnosis in the DOC cohort since mortality data was available up to May 2012, giving a minimum follow-up for death of 2.4 years.

Date of diagnosis, age at diagnosis, date of death and treatment history (radiotherapy and docetaxel) were recorded for all patients. In addition, a 10\% random sample (using random number generator function in Microsoft Excel) of patients from each cohort was selected to identify whether the prevalence of other key prognostic factors differed between groups. This entailed a review of individual medical records to extract key demographic, patient and disease information not available in the registry, radiotherapy and pharmacy databases. Univariate analysis of clinico-pathological characteristics was performed using Chi-squared and student $t$ tests for comparison of risk factors between eras.

To determine whether there was a systematic change in the use of palliative RT to bone (RT-B) during the two eras, we calculated the proportion of men that received RT-B within 1 and 3 years prior to death. For this analysis, we included all men who had died of prostate cancer during each era as the denominator for the proportions.

Survival in the two patient cohorts was calculated from the time of initial palliative radiotherapy. This time point was chosen since the indication for palliative radiotherapy to bone (i.e., onset of symptomatic bone disease, symptomatic or impending spinal cord compression of fracture) remained essentially unchanged over the period of this study. This permitted comparison of the two cohorts at a similar point in their disease progression state. OS was calculated as the time from the first palliative radiotherapy to date of death; OS was estimated using the Kaplan-Meier method. OS in each was compared using the log-rank test.

Variables associated with OS on univariate analysis $(p \leq 0.30)$ were included in a Cox proportional hazards model after proportionality assumptions were confirmed. The following factors were entered into a full stratified Cox proportional-hazards model and a backward selection model, in which non-significant factors were eliminated sequentially at a $p$ level of 0.10 ; these factors included age $(<65$ vs. $\geq 65$ ), metastatic disease at diagnosis (yes vs. no), treatment era (pre-DOC vs. DOC), and receipt of docetaxel (yes vs. no). All statistical analyses were performed using SPSS version 14 (SAS Institute, Cary, NC).

\section{Results}

\section{Patient population}

From 1983 to 2012, 5471 British Columbian men received at least one course of palliative radiotherapy to bone for metastatic prostate cancer. Using the specified inclusion criteria, 1876 men were included in this analysis and grouped into the pre-DOC era $(n=919$ patients; $1998-2001)$ and the DOC era ( $\mathrm{n}=957$ patients; 2006-2009) (Table 1). Patients from the DOC era were significantly more likely to receive docetaxel than those in the pre-DOC era (37\% vs. $7 \%$, $p<0.0001)$. Men in the DOC era were older than those in the pre-DOC era (76.7 years vs. 75.5 years; $p=0.04$ ), but there was no significant difference in the median time from diagnosis to first palliative radiotherapy (3.9 years in the DOC era compared to 3.1 years in pre-DOC era; $p=0.31$ ) or in the proportion of men receiving palliative radiotherapy to bone at 1 year $(34 \%$ vs. $37 \% ; p=0.08)$ and 3 years $(40 \%$ vs. $43 \% ; p=0.20$ ) prior to death. There was also no difference in the proportion of men with metastatic disease present at diagnosis in the DOC and pre-DOC cohorts (33\% vs. $30 \%$; $p=0.09$ ). In randomly selected cohorts comprising $10 \%$ of patients from each era, no differences were seen for other potential prognostic factors between the pre-DOC and DOC groups (Table 2).

Table 1. Baseline and clinical characteristics of patients receiving palliative $R T$ across eras

\begin{tabular}{|c|c|c|c|c|}
\hline Characteristic & Pre-DOC era $(n=919)$ & DOC era ( $n=957)$ & $p$ value & Test \\
\hline Age (median) & 75.5 & 76.7 & 0.04 & t-test \\
\hline $\begin{array}{l}\text { Metastatic disease at } \\
\text { diagnosis, } \mathrm{N}(\%)\end{array}$ & $275(30)$ & $315(33)$ & 0.09 & Fisher exact \\
\hline $\begin{array}{l}\text { Median time from diagnosis to } \\
\text { first palliative RT }\end{array}$ & 3.9 years & 3.1 years & 0.31 & t-test \\
\hline Received DOC, N (\%) & $63(7)$ & $315(33)$ & $<0.0001$ & Fisher exact \\
\hline
\end{tabular}




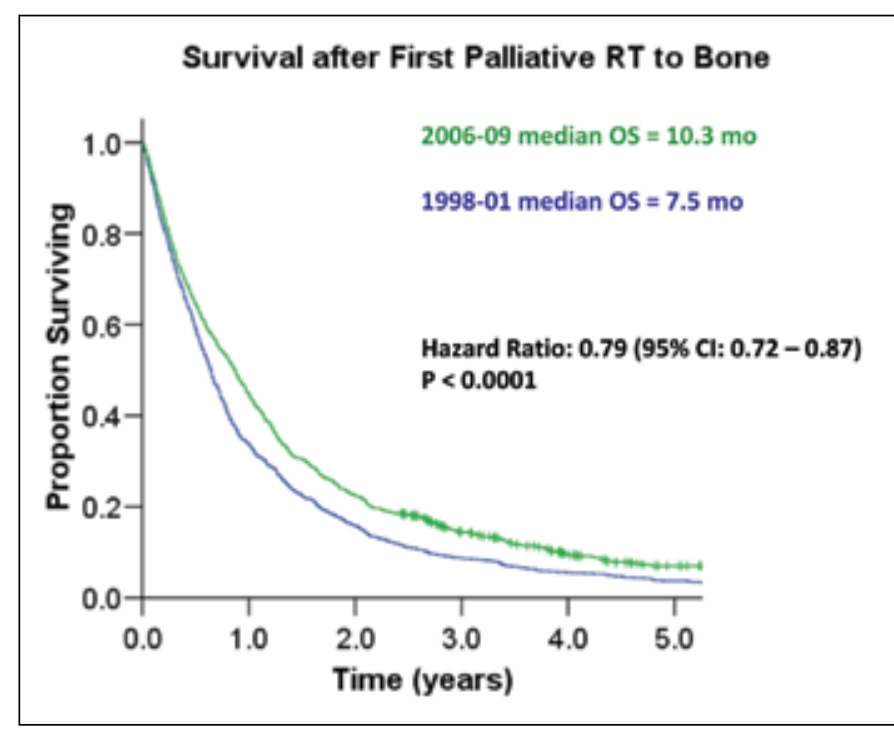

Fig. 1. Kaplan-Meier survival comparisons of patients in the pre-docetaxel (1998-2001) era and the docetaxel era (2006-2009).

\section{Survival analyses}

Median OS was significantly longer in the DOC era $(10.3$ months) compared to the pre-DOC era (7.5 months) (hazard ratio $[H R] 0.79,95 \%$ confidence interval $[\mathrm{Cl}] 0.70-0.89$, $p<0.0001$ ) (Fig. 1). To explore whether there was a population-based dose response effect of docetaxel on OS, we also examined outcomes in patients treated with palliative RT-B from 2004 to 2006 (termed "inter-docetaxel (DOC) era"). During the inter-DOC era, $27 \%$ of patients received docetaxel and the median OS was 8.8 months. Notably, median OS was significantly longer for both the DOC era versus the inter-DOC era (HR 0.91; $p=0.045)$ and the
inter-DOC era versus the pre-DOC era (HR 0.89; $p=0.01)$.

Univariate analysis was performed to examine the association between the following variables and OS: era treated (pre-DOC vs. DOC), treatment with docetaxel (yes vs. no), age at RT ( $<65$ vs. $\geq 65$ ), time from diagnosis to radiotherapy (0-25 years, $2.5-5$ years, $5-10,10-20$, and greater than 20 years) and metastatic disease at diagnosis (yes vs. no). Era treated $(\mathrm{HR} 0.79, p<0.001)$, treatment with docetaxel (HR 0.66, $p<0.001)$ and age at RT (HR 1.01 per year of increased age; $p<0.001$ ) but not time from diagnosis to RT (HR 1.01 per year of increased time; $p=0.50$ ) and metastatic disease at diagnosis (HR 0.95; $p=0.30$ ) were significantly associated with OS. On a multivariable analysis, era treated, treatment with docetaxel and age at RT were confirmed as significant predictors for improved OS (Table 3).

\section{Discussion}

In this study, we examined survival outcomes with docetaxel treatment in a population-based cohort of mCRPC patients, comparing data from pre-DOC (1998-2001) and DOC (2006-2009) eras. Although only $37 \%$ of men received docetaxel in the DOC era, median OS in this era was 2.8 months longer than in the pre-DOC era (HR 0.79). On multivariable analysis, docetaxel administration was confirmed as an independent predictor of OS. The results presented here provide the first evidence of the generalizability of the TAX-327 trial at a population level. Notably, the observed median survival difference in our study is similar to the median OS difference (2.4 months) between the docetaxel and mitoxantrone arms of the TAX-327 study. Likewise, the HR for death (HR 0.76) in the docetaxel treated arm of the TAX-327 study is comparable to our results.

To minimize possible lead-time and selection bias associ-

\begin{tabular}{|c|c|c|c|c|}
\hline Characteristic & Pre-DOC era $(\mathrm{N}=93)^{*}$ & DOC era $(N=94) *$ & $p$ value & Test \\
\hline Gleason score & $\mathrm{n}=56$ & $\mathrm{n}=77$ & 0.47 & Fisher exact \\
\hline$\leq 7(\%)$ & 39 & 32 & & \\
\hline$\geq 8(\%)$ & 61 & 68 & & \\
\hline \multicolumn{5}{|l|}{ At time of first palliative RT } \\
\hline PSA & & & 0.20 & \\
\hline Median (range), $\mu \mathrm{g} / \mathrm{L}$ & $50(0.02,5000)$ & $68(0.2,8400)$ & & t-test \\
\hline ECOG & $\mathrm{n}=73$ & $\mathrm{n}=86$ & 0.26 & Fisher exact \\
\hline $0-1(\%)$ & 53 & 63 & & \\
\hline$\geq 2(\%)$ & 47 & 37 & & \\
\hline Hemoglobin & $117(65,172)$ & $119(52,165)$ & 0.88 & t-test \\
\hline \multicolumn{5}{|l|}{ Median (range), g/L } \\
\hline Medical oncology referral & & & 0.19 & Fisher exact \\
\hline Yes (\%) & 39 & 49 & & \\
\hline No $(\%)$ & 61 & 51 & & \\
\hline
\end{tabular}

DOC: docetaxel; RT: radiotherapy; PSA: prostate-specific antigen; ECOG: Eastern Cooperative Oncology Group. ${ }^{*} \mathrm{n}=93$ for pre-DOC era and $\mathrm{n}=94$ for DOC era unless otherwise specified. 


\begin{tabular}{|c|c|c|}
\hline Variable & HR for overall survival & $p$ value \\
\hline Era treated & 0.84 & 0.001 \\
\hline $\begin{array}{l}\text { Treatment with } \\
\text { docetaxel }\end{array}$ & 0.78 & $<0.001$ \\
\hline Age at RT & $1.02^{*}$ & $<0.001$ \\
\hline $\begin{array}{l}\text { Metastatic disease at } \\
\text { diagnosis }\end{array}$ & 0.93 & 0.18 \\
\hline
\end{tabular}

ated with the non-randomized use of docetaxel, we chose to calculate survival outcomes from the time of initial palliative radiotherapy to bone. We considered the onset of symptomatic bone disease requiring radiotherapy to be a readily identifiable event and one that has not evolved over time since indications for palliative radiotherapy to bone remained unchanged over the study period. By adopting this approach, we identified a similar set of patients at a similar point in their disease course (i.e., the onset of symptomatic bone disease). Our assertion is supported by the comparable utilization of palliative radiotherapy prior to death in the pre-DOC and DOC eras. Importantly, we also found that other routine prognostic factors, including hemoglobin, Gleason score, PSA at diagnosis and PSA doubling time, did not significantly differ between patients from the two eras.

Being a retrospective study, we nevertheless acknowledge the possibility that our survival data may have been influenced by various confounding factors, including stage migration, comorbid diseases, changes to radiation oncology practice and changes in referral patterns to medical oncology. It is also possible that the use of bone-targeted therapies, such as zoledronic acid and denosumab, may have affected the timing of palliative radiotherapy, which in turn could have affected the survival analysis given the study design that we adopted. However, these agents have highly restricted approval in BC and have not gained widespread use. Likewise, although post-docetaxel treatment could have theoretically altered survival outcomes in the DOC era, none of cabazitaxel, enzalutamide, radium-223 or sipuleucel-T was in routine clinical use in $\mathrm{BC}$ before May 2012. Abiraterone was only available for off-trial use as of November 2011. Thus, it appears unlikely that systemic treatment beyond docetaxel greatly influenced survival outcomes in the DOC era.

\section{Conclusion}

This is the first study to confirm that the survival advantage seen with docetaxel in phase III trials in MCRPC patients translates to improved survival outcomes at a population level. The fact that a population-based effect on survival was seen despite just over one-third of patients receiving docetaxel from 2006 to 2009, serves to illustrate the efficacy of docetaxel in mCRPC. Although several other agents with a demonstrated OS benefit in MCRPC are now available, our data reinforce the importance of retaining docetaxel in the therapeutic armamentarium for mCRPC.

Acknowledgements: Dr. Scott Tyldesely has received a Scholar award funding from the Michael Smith Foundation for Health Research for protected research time.

Competing interests: Dr. Zielinski declares no competing financial or personal interests. Dr. Azad has received research funding from Astellas. Dr. Chi has received research funding from OncoGenex Technologies Inc., Astellas, Janssen, and Novartis and is a consultant for Janssen, Astellas, Amgen, Bayer, Millennium, Novartis, and Sanofi. Dr. Tyldesely has received speakers and consultant honoraria from Janssen, Astellas, Astra-Zeneca, Amgen, and Sanofi-Aventis.

This paper has been peer-reviewed.

\section{References}

1. Tannock IF, de Wit R, Berry WR, et al. Docetaxel plus prednisone or mitoxantrone plus prednisone for advanced prostate cancer. N Engl J Med 2004;351:1502-12. http://dx.doi.org/10.1056/ NEJMoo040720

2. Petrylak DP, Tangen $C M$, Hussain MH, et al. Docetaxel and estramustine compared with mitoxantrone and prednisone for advanced refractory prostate cancer. N Engl J Med 2004;351:1513-20. http:// dx.doi.org/10.1056/NEJMoa041318

3. Scher HI, Fizazi K, Saad F, et al. Increased survival with enzalutamide in prostate cancer after chemotherapy. N Engl J Med 2012;367:1187-97. http://dx.doi.org/10.1056/NEJMoal 207506

4. de Bono JS, Logothetis $\mathrm{CJ}$, Molina A, et al. Abiraterone and increased survival in metastatic prostate cancer. N Engl J Med 2011;364:1995-2005. http://dx.doi.org/10.1056/NEJMoa1014618

5. de Bono IS, Oudard S, Ozguroglu M, et al. Prednisone plus cabazitaxel or mitoxantrone for metastatic castration-resistant prostate cancer progressing after docetaxel treatment: A randomised open-label trial. Lancet 2010;376:1147-54. http://dx.doi.org/10.1016/S0140-6736(10)61389-X

6. Parker C, Nilsson S, Heinrich D, et al. Alpha emitter radium-223 and survival in metastatic prostate cancer. N Engl J Med 2013;369:213-23. http://dx.doi.org/10.1056/NEJMoal213755

7. Kantoff PW, Higano CS, Shore ND, et al. Sipuleucel-T immunotherapy for castration-resistant prostate cancer. N Engl J Med 2010;363:411-22. http://dx.doi.org/10.1056/NEJMoa1001294

8. Harris $\mathrm{V}$, Lloyd K, Forsey $\mathrm{S}$, et al. A population-based study of prostate cancer chemotherapy. Clin Oncol (R Coll Radiol) 2011;23:706-8. http://dx.doi.org/10.1016/i.clon.2011.04.014

9. Engel-Nitz NM, Alemayehu B, Parry D, et al. Differences in treatment patterns among patients with castration-resistant prostate cancer treated by oncologists versus urologists in a US managed care population. Cancer Manag Res 2011;3:233-4.

Correspondence: Dr. Scott Tyldesely, BC Cancer Agency, 600 West 10 $10^{\text {th }}$ Ave, Vancouver, British Columbia, Canada V5Z 4E6; styldes@@bccancer.bc.ca 